\title{
Sex-specific stoichiometric niche, nutrient partitioning and resource allocation in a solitary bee
}

\author{
Michał Filipiak $^{1}$, Michal Woyciechowski ${ }^{1}$, and Marcin Czarnoleski ${ }^{1}$ \\ ${ }^{1}$ Jagiellonian University in Krakow
}

April 28, 2020

\begin{abstract}
Nutritional limitations imposed on populations may shape species life histories. However, populations consist of individuals belonging to different sexes and life stages, each with specific nutritional demands and limitations. Taking this into account, we used the ecological stoichiometry framework to study the budgets of twelve elements in both sexes of the solitary bee Osmia bicornis under natural conditions. We considered the stoichiometric niche and elemental transfer from larval food to the adult body and cocoon, studying the multielemental composition of food (pollen), eggs, pupae, adults, cocoons and excreta. The sexes differed fundamentally in their elemental phenotypes, stoichiometric niches, and assimilation and allocation of acquired atoms for all the elemental budget components, including elements beyond those most commonly studied (C, N and P). Sexual dimorphism in nutritional limitation occurring in different life cycle stages may influence bee population functioning and should be considered in bee conservation efforts.
\end{abstract}

\section{Hosted file}

Sex_specific_stoichiometric_niche_MAIN_MANUSCRIPT_final_MF.doc available at https://authorea . com/users/307451/articles/438745-sex-specific-stoichiometric-niche-nutrient-partitioningand-resource-allocation-in-a-solitary-bee 

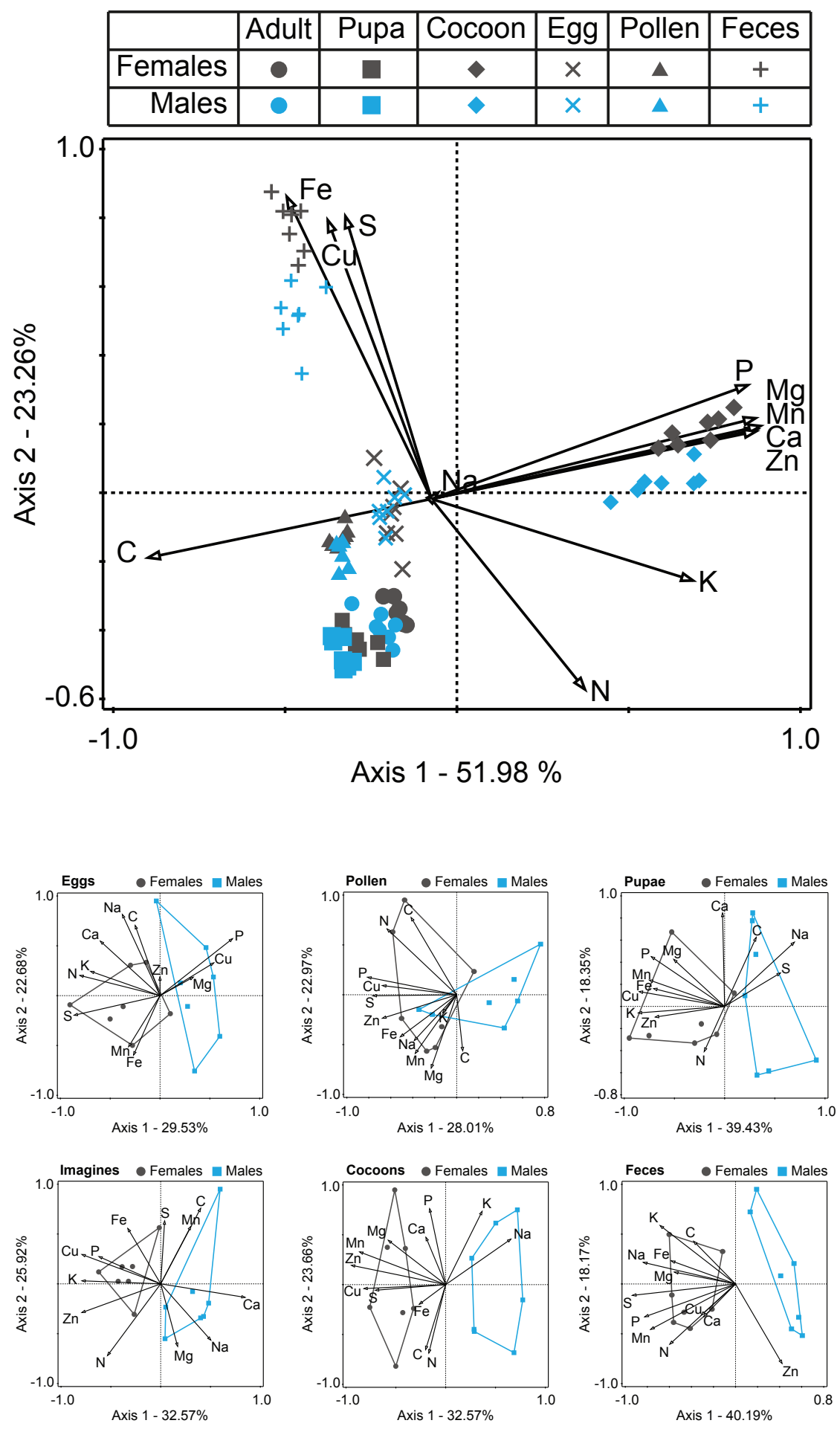

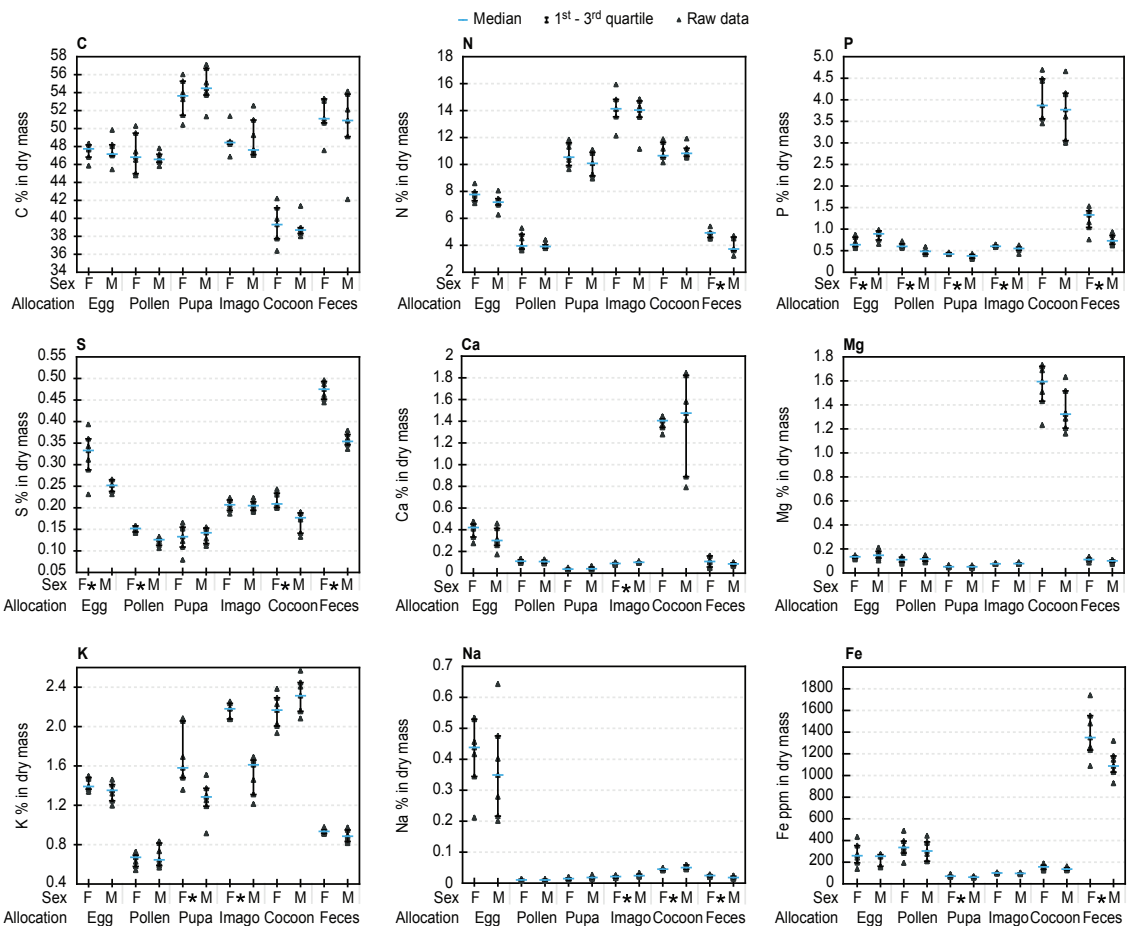

Allocation Egg Pollen Pupa Imago Cocoon Feces
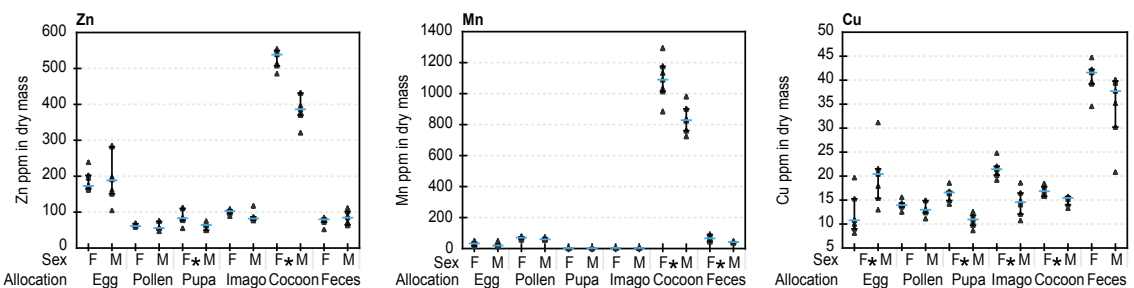
- Median - females - Median - males I Quartile range (25\%-75\%)
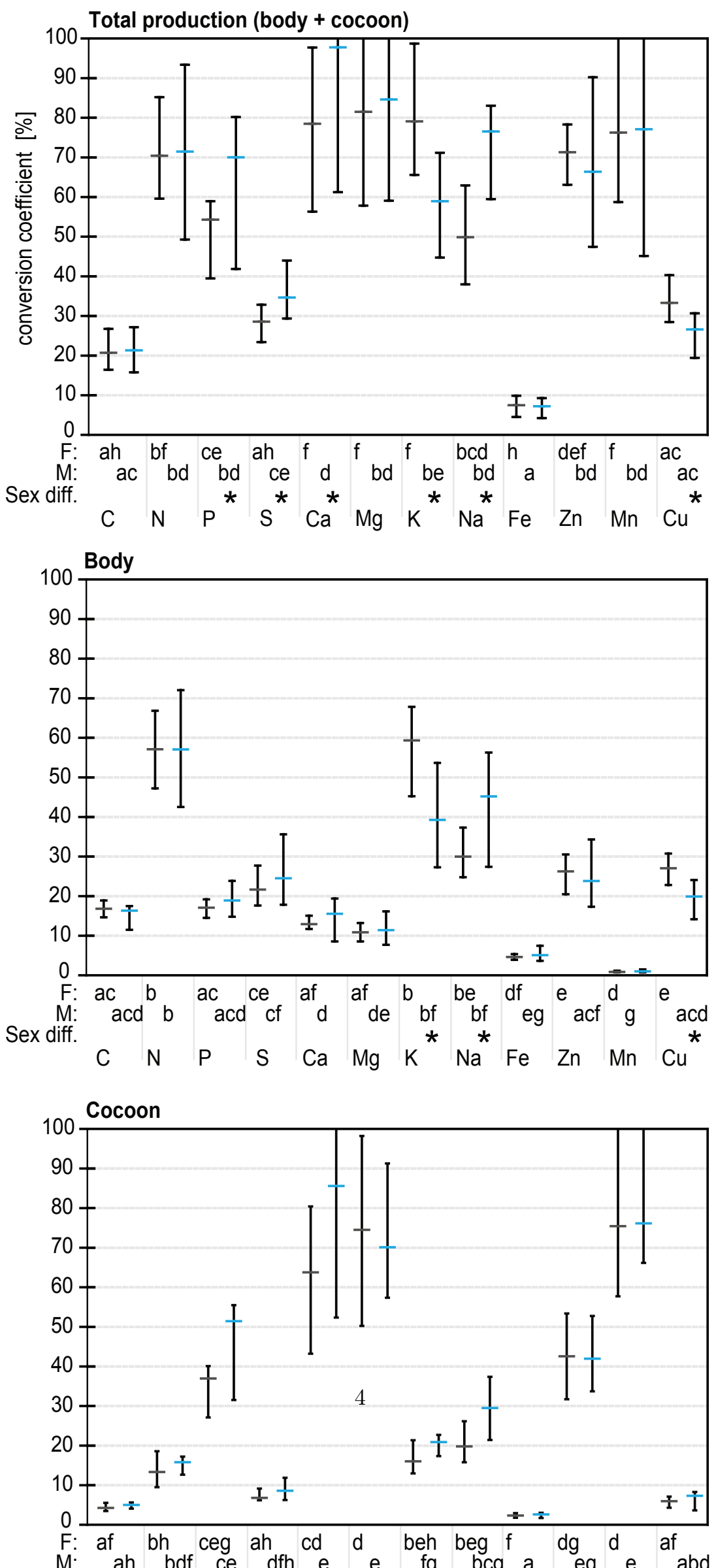


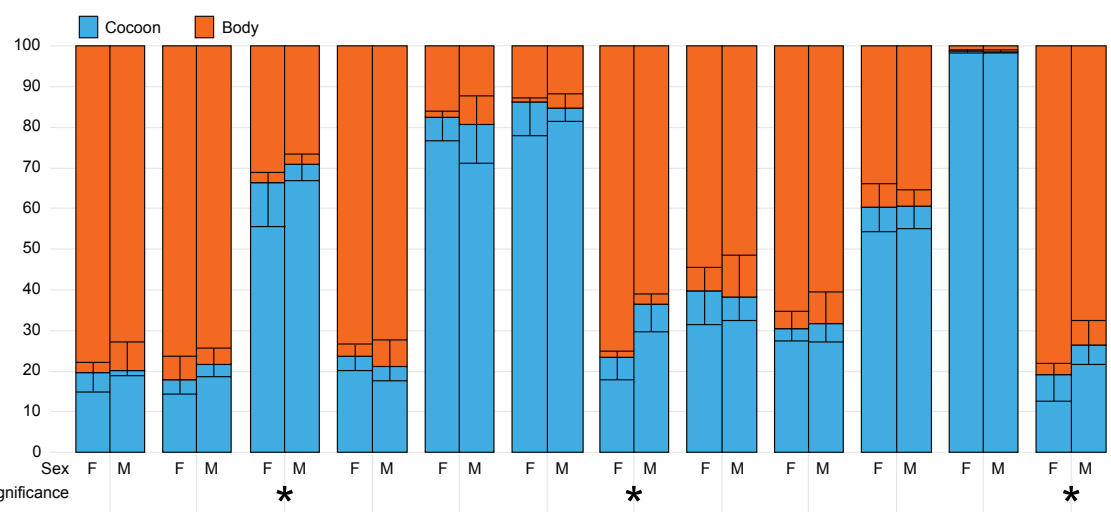
Significance

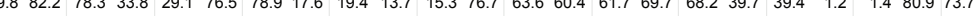

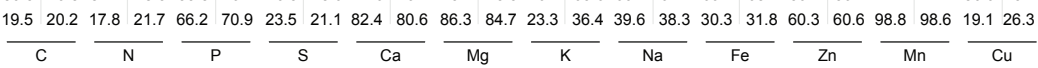

